\title{
O Voluntariado e o Servidor Público: o Caso dos Técnicos-Administrativos em Educação da Universidade Federal do Vale do São Francisco (UNIVASF)
}

Dâmaris Yana Ribeiro ${ }^{1}$, Francisco Alves Pinheiro ${ }^{2}$, Leonardo Rodrigues Sampaio ${ }^{3}$

\begin{abstract}
Resumo: O voluntariado, apesar de não ser um fenômeno recente, passou a ter maior visibilidade e a fazer parte das políticas governamentais de vários países após o ano de 2001 ter sido eleito o Ano Internacional do Voluntariado. No Brasil, o governo federal reconhecendo a importância do voluntariado para a coesão e o desenvolvimento da sociedade, expediu o Decreto $n^{\circ}$ 9.149/2017, instituindo o Programa Nacional de Voluntariado (PNV) e enfatizando a necessidade de parceria entre Estado, sociedade e o setor privado para fomentar o trabalho voluntário. Entre outros objetivos do PNV, foi estabelecido que caberá aos órgãos da Administração Pública Federal estimular o voluntariado e incentivar os servidores a praticarem esse tipo de atividade. Assim, o objetivo da pesquisa foi analisar a percepção do voluntariado a partir da perspectiva dos técnico-administrativos em educação (TAEs) da Universidade Federal do Vale do São Francisco (Univasf). Para tanto, a metodologia adotada foi de abordagem quantitativa, utilizando um questionário e os instrumentos: Inventário de Funções do Voluntariado (IFV) e também a Bateria de Personalidade Pró-social (BPP), que são validados a nível nacional, contemplando uma amostra de 161 TAEs. Obteve-se com o resultado dados significativos para auxiliar a Univasf, e, possivelmente, outras universidades públicas, a formular políticas e ações de estímulo e incentivo a atividades voluntárias entre seus servidores públicos, atentando-se para as particularidades do público-alvo, desde a sua percepção até a motivação.
\end{abstract}

Palavras-chave: Voluntariado. Percepção. Motivação. Serviço Público Federal. Técnico-administrativo em educação. Univasf.

\section{Volunteering and Public Servants: The Case of the Administrative Technicians in Education of the Federal University of the São Francisco Valley (UNIVASF)}

Abstract: Volunteering, although not a recent phenomenon, became more visible and part of the governmental policies of several countries after 2001 was elected International Year of Volunteering. In Brazil, the federal government recognized the importance of volunteering for the cohesion and development of society, issued Decree 9.149 / 2017, instituting the National Volunteer Program (PNV) and emphasizing the need for partnership between the State, society and the private sector to encourage volunteer work. Among other objectives of the PNV, it was established that it will be up to the organs of the Federal Public Administration to stimulate volunteering and

\footnotetext{
${ }^{1}$ Mestranda em Administração Pública do PROFIAP/UNIVASF, Petrolina -PE, Brasil.

Contato: damarisyr@gmail.com

2 Engenharia Agronômica pela Universidade Federal do Ceará, mestrado em Engenharia de Produção pela Universidade Federal da Paraíba e doutorado em Segurança e Saúde Ocupacionais pela Universidade do Porto, Portugal. Professor adjunto da Universidade Federal do Vale do São Francisco - UNIVASF, Petrolina - PE, Brasil.

Contato: francisco.pinheiro@univasf.edu.br

${ }^{3}$ Licenciatura Plena e Formação em Psicologia pela Universidade Estadual da Paraíba. Mestrado e Doutorado em Psicologia Cognitiva pela Universidade Federal de Pernambuco e Pós-doutorado pela Harvard Graduate School of Education. É Professor Associado da Fundação Universidade Federal do Vale do São Francisco - UNIVASF, Petrolina - PE, Brasil. Contato: leonardo.sampaio@univasf.edu.br
} 
encourage the employees to practice this type of activity. Thus, the objective of the research was to analyze the perception of volunteering from the perspective of the administrative technicians in education (TAEs) of the Federal University of the São Francisco Valley (Univesf). To that end, the methodology adopted was a quantitative approach, using a questionnaire and the instruments: Volunteer Functions Inventory (IFV) and Pro-Social Personality Battery (BPP), which are validated at a national level, including a sample of 161 TAEs. Significant data were obtained to assist Univasf and, possibly, other public universities, to formulate policies and actions to stimulate and encourage voluntary activities among its public servants, taking into account the particularities of the target public, since your perception to the motivation.

Keywords: Volunteering. Perception. Motivation. Federal Public Service. Technical-administrative in education. Univasf.

\section{Introdução}

A atividade voluntária esteve presente em diferentes culturas e momentos históricos. Inicialmente, o voluntariado era relacionado às organizações religiosas e étnicas, por meio de ações com características mais voltadas para caridade e de maneira pontual. Posteriormente, a atividade voluntária passou a ser vista como um mecanismo de participação dos indivíduos e o exercício da cidadania, definindo um comportamento pró-social (SODRÉ, 2012). Este comportamento é crucial, já que o modelo do Estado de Bem-Estar Social, configurado para atender o máximo de vantagens aos cidadãos que exercem ações de voluntariado, apresentou dificuldades em elucidar as demandas sociais, apresentando deficiências na prestação dos serviços (VITALIS, 2015).

Constata-se que a atuação do voluntário é significativa, visto que, diferente dos demais profissionais, participa de ações sociais de forma espontânea e gratuita, visando desempenhar atividades em benefício de terceiros, do bem comum e desenvolvimento da sociedade. Para Sapiro e Matiello (2016, p. 2), “o voluntário da atualidade não se limita a socorrer os mais necessitados, mas busca promoção de mudanças e transformação social, transcende interesses individuais e se coloca no campo da cidadania, uma preocupação não apenas com o "eu", mas com o "outro" e o mundo". Também foram comprovados alguns benefícios para quem pratica ações voluntárias, tais como aumento da felicidade, melhoria na saúde física, diminuição da ansiedade, redução do estresse e qualidade do sono (SAPIRO; MATIELLO, 2016), etc. 
Reconhecendo a importância do voluntariado, o Governo Federal criou no Brasil, por meio do Decreto $n^{\circ}$ 9.149/2017, o Programa Nacional de Voluntariado (PNV), instituindo o Prêmio Nacional do Voluntariado e alterando o Decreto $n^{\circ} 5.707 / 2006$, que institui a Política e as Diretrizes para o Desenvolvimento de Pessoal da administração pública federal direta, autárquica e fundacional. O PNV busca, dentre outras finalidades, "promover o voluntariado de forma articulada entre Governo, organizações da sociedade civil e o setor privado".

O referido decreto criou também o Conselho Gestor do PNV, a fim de "estimular os órgãos da administração direta autárquica e fundacional a promoverem o voluntariado e incentivar servidores públicos à participação em atividades voluntárias”. Desta forma, nota-se que o trabalho voluntário evoluiu do aspecto meramente assistencialista para um patamar de importância que resultou em status de legalidade.

No entanto, para que a atuação dos órgãos públicos possa ser efetiva, faz-se necessário saber como servidores públicos federais percebem o voluntariado e entendem o que os motiva ou motivaria a serem voluntários (AGOSTINHO, 2011; RODRIGUES, 2014), inclusive no viés das universidades públicas federais, a exemplo da Universidade Federal do Vale do São Francisco (Univasf), lócus do presente estudo. Com isso, este estudo busca elucidar a seguinte questão central: Qual a percepção dos TAEs da Univasf sobre o voluntariado?

\section{Referencial Teórico}

\section{Voluntariado: Vertentes Conceituais e Tipologias}

Parte do embasamento do estudo científico de fenômeno social reside na delimitação do objeto e dos vários conceitos que são relacionados (AGOSTINHO, 2011). No entanto, estabelecer limites em qualquer área de estudo exige muita atenção, visto que existe o risco de haver interpretação errônea de alguma teoria e, também, uma abordagem sucinta do conteúdo. O voluntariado, enquanto fenômeno social, não é percebido como acontecimento recente (RAMOS, 2012; MARCOS; AMADOR, 2014), já que tem sido uma das práticas humanas mais básicas e deriva-se dos antigos costumes de trocas e partilhas. 
O voluntariado decorre da articulação do indivíduo na sua comunidade e é intrínseco ao exercício da cidadania, traduzindo-se em ações solidárias que estiveram presente de forma regular em quase todas as sociedades e culturas, sendo relacionadas a cuidados voltados para pessoas necessitadas, enfermas, entre outros cenários de vulnerabilidade. (MARQUES, 2016). Para Sapiro e Mattiello (2016, p. 2), "o voluntariado é caracterizado pelo ato de uma pessoa doar tempo e conhecimento em prol da sociedade em que vive, com ações não remuneradas, de valor para a comunidade ou o próximo". Para os autores, o serviço voluntário favorece atos de generosidade e de beneficência entre as pessoas, todavia é importante compreender formas e abordagens de classificação da atividade voluntária: formal e informal.

Entende-se por voluntariado formal as ações de ajuda ao próximo que são realizadas por meio de organizações sem fins lucrativos, proporcionando benefícios para a sociedade e ao voluntário, através da oferta de serviços sociais (AGOSTINHO, 2011; MARQUES, 2016). Por sua vez, o trabalho voluntário informal abarca todas as demais ações voluntárias que não estão relacionadas a uma organização, tais como ajudar os familiares, amigos, etc. (RAMOS, 2012; MARCOS; AMADOR, 2014; MARQUES, 2016). A categoria do voluntariado formal pode ser subdividida em dois tipos: dirigente e não-dirigente. $\mathrm{O}$ voluntariado dirigente, também conhecido como de direção, envolve voluntários que compõem os órgãos de gestão e realizam atividades de manutenção da própria organização. Esta categoria abrange o número menor de voluntários e está relacionada às atividades meios das instituições, exercendo o papel de ligação entre os voluntários e as organizações. O voluntariado não-dirigente, por sua vez, representa as ações desenvolvidas de uma forma direta, em que há relação imediata entre voluntário e a comunidade em que atua (MARCOS; AMADOR, 2014; AGUIAR; SILVA; DIAS, 2015).

$\mathrm{O}$ voluntariado ainda pode ser dividido, quanto à periodicidade, em regular, ocasional $\mathrm{e}$ pontual. Segundo Ramos (2012), o voluntário ocasional é envolvido em atividades de curto prazo ou específicas. Enquanto que o voluntário regular é aquele desenvolvido de maneira assídua com regularidade. Conforme Marques (2016) o voluntariado é considerado regular ou contínuo quando a atividade voluntária é desenvolvida pelos menos uma vez por mês no intervalo de um ano, pelo menos. 


\section{Normativos Legais do Voluntariado}

O serviço voluntário somente foi regularizado com a publicação da Lei nº 9.608/1998, que, segundo Vitalis (2015), foi elaborada de forma sucinta em comparação à legislação de outros países, tais como, a legislação de Portugal que é mais minuciosa ao conceituar e definir os princípios que regem o voluntariado, por exemplo.

Percebe-se que o legislador procurou trazer o conceito do serviço voluntário e também apresentou elementos importantes para a configuração do desempenho da atividade voluntária, a saber: a realização de atividade não remunerada, a não caracterização do vínculo empregatício, a possibilidade de ressarcimento das despesas comprovadas pelo voluntário e a possibilidade de exercer o voluntariado em instituições públicas ou privadas, desde que esta não tenha fins lucrativos, e a sua atuação esteja relacionada aos objetivos cívicos, culturais, educacionais, científicos, recreativos ou de assistência à pessoa, sendo esta última incluída pela Lei $\mathrm{n}^{\circ}$ 13.297/2016 (VITALIS, 2015).

Mesmo com vigência da Lei do Voluntariado, ainda era enfatizado por Selli e Garrafa (2006) que no Brasil não havia canais de acesso bem-estruturados que facilitassem ou que estimulassem a ação voluntária, não existindo, nesse sentido, o reconhecimento social capaz de reforçar o sentimento de gratificação do voluntariado. Assim, o Presidente da República expediu o Decreto ${ }^{\circ}$ 9.149, de 28 de agosto de 2017, dispondo sobre a criação do Programa Nacional de Voluntariado (PNV), instituição do Prêmio Nacional de Voluntariado e alterando artigos do Decreto 5.707/2006 que trata da Política e das Diretrizes para o Desenvolvimento de Pessoal da administração pública federal direta, autárquica e fundacional.

O Programa Nacional de Voluntariado (PNV), conforme o art. $1^{\circ}$, foi criado com o fim de promover uma articulação entre o Governo, as organizações da sociedade civil e o setor privado, buscando incentivar o engajamento social, junto com a participação cidadã, em ações sociais transformadoras, primando pelo alcance de Objetivos de Desenvolvimento Sustentável da Agenda 2030. Criou-se, a partir do supracitado normativo, o Conselho Gestor do Programa Nacional de Voluntariado, composto por representantes de órgãos públicos, do setor privado e também de organizações da sociedade civil. 


\section{O Voluntariado na Universidade e a Inclusão dos Servidores Públicos Federais}

O interesse pelas IES pelo voluntariado surgiu em virtude das mesmas, possuírem espaço adequado para incentivo e prática da atividade voluntária, que são fundamentais para o desenvolvimento do voluntariado. A universidade pode ser percebida como uma instituição estratégica para a inserção de cultura de voluntariado, já que tem, por finalidade, capacitar cidadãos, acolhendo indivíduos que ainda estão em formação, permitindo que o conhecimento sobre o trabalho voluntário seja melhor assimilado. Desse modo, Cavero Sibelli $(2015$, p. 8) assegura que: "as chances de obter gerações de cidadãos comprometidos com uma sociedade equitativa e de seres humanos que praticam diariamente e não esporadicamente os valores que impulsionam o voluntariado são criados".

Dessa forma, compreende-se que para uma IES que queira ser reconhecida pelo seu engajamento com o desenvolvimento do país, a implantação de um programa de voluntariado bem estruturado passa a ser uma ótima oportunidade de transformar esse ideal em realidade (NEVES, 2006). E que embora a ênfase do voluntariado no âmbito acadêmico seja dada aos discentes, a universidade é formada por servidores públicos, devendo destinar a atenção para esse segmento de profissionais. Com a expedição do novo decreto presidencial, Decreto $\mathrm{n}^{\mathrm{o}}$ 9.149/2017, caberá aos órgãos da Administração a promoção do voluntariado e o incentivo aos servidores para a prática de atividades voluntárias.

A participação do servidor público nas ações de voluntariado das universidades, no entanto, ainda não tem sido abordada na literatura especializada, em parte pela determinação do decreto presidencial ser recente, ficando, assim, a atenção voltada sobretudo para a participação dos discentes. No entanto, cabe destacar que as universidades compreendem uma tríade que corresponde a sua função-fim que são o ensino, a pesquisa e a extensão, mas que para atingir a sua finalidade, faz-se necessária a participação dos servidores (COUTINHO; DIOGO; JOAQUIM, 2008). Por meio de argumentos dos autores, a instituição compreende os servidores TAEs, uma vez que estes são encarregados pela administração e pelos serviços de apoio, consideradas atividades-meio, nem sempre recebem atenção nas políticas públicas e internas das instituições de educação (COUTINHO; DIOGO; JOAQUIM, 2008).

Para Faria, Leite e Silva (2017, p. 542) “os serviços da área-meio não possuem caráter de produção, mas de apoio, têm pouca visibilidade social e, frequentemente, dependem de uma 
cadeia de serviços que se entrelaçam para serem concluídos”. Esse suporte sistemático de atividades deve consideravelmente refletir na execução das tarefas realizadas pelos servidores públicos, produzindo uma melhoria contínua na imagem da organização, do servidor e conferindo maior valor agregado ao serviço. A inclusão dos TAEs em ações voluntárias pode trazer benefícios para os mesmos, a exemplo da saúde, pois, para Faria, Leite e Silva (2017, p. 543) "o trabalhador do setor público é estigmatizado, sendo considerado privilegiado por ter um emprego estável, como se não estivesse submetido a condições de trabalho que podem levar ao sofrimento e adoecimento".

O voluntariado universitário deve ser, portanto, priorizado como uma política pública e estimulado pela gestão da universidade, buscando sensibilizar, principalmente, a alta direção e demais chefias ao demonstrar vantagens da implementação de um programa de voluntariado para a própria universidade e, principalmente, para funcionários (NEVES, 2006). Tendo em vista que para a gestão pública ser efetiva precisa disponibilizar capacitação para servidores. E o voluntariado proporciona maior envolvimento que transparece em gesto e atitudes com benefícios (SAPIRO; MATTIELLO, 2016, p. 4). Mostra-se, portanto, relevante a inclusão dos TAEs nas ações e políticas universitárias, para que possam sentir-se valorizados ao participar da evolução social da IES.

\section{Metodologia}

O estudo foi realizado a partir de análise descritiva da percepção do servidor público federal em relação ao voluntariado e a sua motivação para esse tipo de atividade. E quanto à natureza da pesquisa, foi aplicada a abordagem quantitativa. A pesquisa foi desenvolvida por meio de estudo de caso, que, para Noor (2008), um estudo de caso pode ser entendido como particularizado de um programa, de uma pessoa ou unidade social, por exemplo.

Neste contexto, o ambiente de pesquisa foi a Universidade Federal do Vale do São Francisco (Univasf), que conta com 882 servidores entre docentes e servidores da carreira técnico-administrativo em educação (TAE). Neste estudo, o universo da pesquisa contempla apenas os TAEs da Univasf, que correspondem ao total de 353 servidores públicos (40\% do universo de servidores públicos da instituição). A estimativa do tamanho da amostra aleatória 
simples, considerou nível de confiança de $95 \%$ e, com isso, definido em 185 o número de participantes para amostra estatisticamente representativa da população.

Cabe frisar que a amostra definida, de início, era de 185 participantes, mas somente 161 TAEs se dispuseram a participar da pesquisa, ou seja, 87,03\%. A coleta de dados foi feita via internet, em questionário, através do Formulário do Google, e os TAEs foram convidados a participar por meio do e-mail institucional com informações sobre este estudo e o link para acessar o questionário online, enfatizando que as informações eram anônimas e confidenciais. A pesquisa foi protocolada sob Certificado de Apresentação para Apreciação Ética (CAAE) $n^{\circ}$ 83913318.8.0000.5196 e aprovada pelo Comitê de Ética em Pesquisa (CEP) da Univasf, conforme o parecer consubstanciado do CEP $\mathrm{n}^{\circ}$ 2.876.965.

Foi desenvolvido pré-teste para averiguar as conformidades do questionário e as possíveis necessidades de ajustes, após a sua aprovação, a versão do instrumento final foi aplicado, contemplando perguntas do tipo fechadas de múltipla escolha e algumas abertas. De forma complementar ao questionário, foram usados os seguintes instrumentos: Bateria de Personalidade Pró-social (Prosocial Personality Battery) e também o Inventário de Funções do Voluntariado (Volunteer Functions Inventory).

Os dados foram tabulados e organizados na planilha eletrônica do Excel e sua análise foi feita através de estatística descritiva com a utilização do Statistical Package for Social Sciences (SPSS). O nível de significância adotado para a análise dos dados foi de $\mathrm{p} \leq 0,05$ e o erro máximo permitido foi de 5\%. O teste de Kolmogorov-Smirnov foi realizado para verificar se os dados tinham uma distribuição normal, e foi constatado que os dados não seguiam uma distribuição normal, sendo necessária o uso de testes não paramétricos.

\section{Análise e Discussão dos Resultados}

\section{Perfil Sociodemográfico dos Participantes}

Mediante a verificação dos dados coletados, observou-se que, dos 161 TAEs participantes da pesquisa, a maioria é do sexo feminino $(57,8 \%)$, com a idade variando dos 25 aos 66 anos. A maior parte dos respondentes é composta por servidores públicos casados ou que estão em uma união estável 
(60,9\%), além de terem filhos $(60,2 \%)$. No que diz respeito à religiosidade, o maior número de respondentes é católico $(50,3 \%)$ e a média de avaliação da frequência com que os participantes praticam e vivenciam a sua religião foi de 3,09, em uma escala de cinco pontos, variando de "muito baixa" a "muito alta". Quanto à importância da religião na vida, a média foi de 3,91, que variava de "nada importante" a "extremamente importante".

No âmbito profissional, a maioria possui curso de pós-graduação completa (especialização, mestrado ou doutorado) $(68,3 \%)$. Em relação ao tempo de ingresso, na Univasf, há variação de 1 mês a 170 meses, com média de 87,78 meses, que equivale a cerca de 7 anos e alguns meses e o campus da universidade que obteve uma maior representatividade foi o campus Petrolina/PE - Sede $(61,5 \%)$.

\section{Prática do Voluntariado Entre os Taes da UNIVASF}

Tendo em vista que a pesquisa foi realizada com a categoria dos TAEs da Univasf, constatouse que dos 161 participantes da amostra, 24,8\% estão atuando como voluntários, enquanto que 75,2\% não estão realizando atividade considerada como voluntária. Quanto à idade, a pesquisa desenvolvida com os TAEs da Univasf, apurou-se que a faixa etária predominante, entre participantes que compõem a categoria dos indivíduos que estão realizando atividade voluntária, compreende dos 25 aos 40 anos de idade, representando $75 \%$ da respectiva categoria.

Do percentual de não praticantes de ações de voluntariado, 17,4\% foram voluntários há menos de 5 anos, 23\% foram voluntários há mais de 5 anos e 34,8\% nunca foram voluntários. E os mesmos afirmaram que o tempo médio dedicado ao trabalho voluntário é de 3,45 horas por semana, ficando a média do período em que exercem esse tipo de atividade em 82,75 meses, o equivalente a 7 anos, aproximadamente.

Ao serem questionados sobre a época que atuaram como voluntários, afirmaram que a duração das práticas voluntárias variava entre 2 a 20 horas por semana, ficando a média de 4,79 horas/semana. Quando inquiridos se haviam realizado o voluntariado através de instituições, sejam elas públicas ou privadas, 16 dos participantes responderam que $\operatorname{sim}(57,1 \%)$, enquanto, 12 participantes responderam negativamente $(42,9 \%)$. O número encontrado de voluntários dentro da amostra pesquisada foi de 40 participantes, ou seja, $24,8 \%$ dos envolvidos.

Ainda com base nos resultados, foi possível verificar que 55\% dos TAEs voluntários exercem a atividade voluntária por meio de organizações sociais ou instituições, públicas ou privadas, enquanto $45 \%$ não realizam. Este tipo de participação configura o voluntariado formal (AGUIAR; SILVA; DIAS, 
2015; MARQUES, 2016), já que este tipo de voluntariado está mais relacionado aos grupos, às organizações ou também instituições, depreendendo-se, pois, que a maioria dos participantes realizam voluntariado formal. As organizações mais citadas, nesse sentido, como alvo das ações voluntárias foram: igrejas, universidades, hospitais, escolas, instituições filantrópicas dentre outras.

Ao serem questionados sobre as principais áreas de intervenção em que atuavam, a maioria elegeu a ação social com 27,4\%, seguindo-se a educação com 19\%. Cabe ressaltar que os participantes poderiam escolher mais de um tipo de área de intervenção. E na categoria "outras" foram agrupadas as áreas jurídica e religiosa, equivalente a 4,8\%. Este resultado é favorável para a Univasf, uma vez que as áreas sociais e educação são inerentes ao próprio papel desempenhado pela universidade, no tocante aos segmentos em que atua no contexto político e também social (THIEL, 2012), o que facilitará a implementação de ações nesses segmentos e a maior participação dos TAEs.

A regularidade da participação dos indivíduos em trabalhos voluntários pode ser, geralmente, associada às motivações dos mesmos, mas também pode advir dos benefícios resultantes desse tipo de atividade. Corroborando este entendimento, Penner (2002) alega que antes que as pessoas concordem em se voluntariar, existe alguma ponderação sobre os custos e benefícios de se envolver em ações voluntárias. Partindo desse pressuposto, os TAEs voluntários foram inquiridos sobre quais benefícios consideravam mais importantes decorrentes do voluntariado e os mais escolhidos foram: participação ativa na sociedade e a realização pessoal, ambos escolhidos por 27 participantes cada. É importante frisar que os participantes poderiam escolher mais de um tipo de benefício, elencando os mais relevantes. O posicionamento dos TAEs voluntários é compreensível, visto que, o ato de voluntariar-se é uma forma de envolvimento do indivíduo no contexto social e a participação voluntária está pautada no senso das obrigações em prol da sociedade.

Tendo em vista que uma das características que distingue o voluntariado de outras formas de comportamento pró-social é, justamente, o "seu caráter planejado, sustentado e contínuo" (PILATI; HEES, 2011, p. 275), o lapso temporal de mais de 5 anos demonstrou ser suficiente para modificar os comportamentos e motivações dos indivíduos frente ao voluntariado, visto que, os testes realizados ao longo do estudo. Em relação aos motivos que incitam os indivíduos a tornarem-se voluntários, entre os que foram voluntários há mais de 5 anos e dos que não foram voluntários, a maioria dos participantes (62) escolheu a realização pessoal. Conhecer novas realidades e participar ativamente na sociedade também foram motivos bastantes apontados pelos respondentes. Enquanto que adquirir experiência profissional só foi escolhido por 21 dos inquiridos. É necessário enfatizar que eles poderiam escolher mais de um motivo. 
Estudos apontam que as relações sociais informais também têm a sua parcela de contribuição em aumentar as oportunidades de envolvimento em atividades voluntárias, além das organizações sociais formais (MATSUBA; HART; ATKINS, 2007). Assim, é comum pessoas serem recrutadas para o voluntariado através de amigos e familiares. Da pesquisa, foi possível verificar que, entre os motivos que incitam para o voluntariado, família e amigos foram escolhidos por 29 e 31 participantes, respectivamente. Estudos revelam que outras influências do voluntariado são resultantes dos fatores socioeconômicos, culturais e demográficos (MATSUBA; HART; ATKINS, 2007). Nesse sentido, Wilson (2000) afirma que é possível perceber indicadores para o voluntariado a partir da idade, do sexo, da renda familiar, do nível de escolaridade, bem como da religiosidade.

Em relação ao sexo face ao voluntariado, na presente pesquisa, nota-se que as mulheres são a maioria nas três categorias, quais sejam: dos TAEs voluntários $(52,5 \%)$, dos que foram voluntários há menos de 5 anos $(67,86 \%)$, dos que foram voluntários há mais de 5 anos $(59,46 \%)$ e dos que nunca foram voluntários $(55,36 \%)$. No entanto, o teste Qui-quadrado não demonstrou diferença significativa do sexo dos participantes em função da prática do voluntariado.

No que se refere ao tempo dispensado nas atividades voluntárias, percebe-se que o sexo feminino possui média de 88,48 meses de atuação, enquanto o masculino tem média de 76,42 , cabe esclarecer que, em virtude dessa variável apresentar valores extremos, utilizou-se a mediana como complementação, visto que a média foi pouco representativa da amostra. E o teste de Mann-Whitney também não indicou diferenças significativas nos tempos médios de atuação voluntária.

Vários estudos foram desenvolvidos com o intuito de perceber se existia alguma associação entre a prática do voluntariado e o sexo de quem pratica atividades voluntárias, e concluiu-se que há uma maior participação feminina do que masculina, sendo, no entanto, a diferença pouco significativa (MARQUES, 2016). Segundo a pesquisa nacional feita pelo IBGE (2018), o voluntariado no país é praticado, principalmente, por mulheres, com o percentual de $5,1 \%$.

No tocante à prática do voluntariado em relação ao estado civil dos participantes, consoante Wilson e Musick (1999, p. 164), "o estado civil e a presença de crianças no domicílio são fatores que aumentam o voluntariado". Na pesquisa desenvolvida foi possível verificar que dos 46 participantes solteiros, apenas 10 estão realizando atividade voluntária. Dos 98 casados/união estável, 24 realizam voluntariado. Enquanto que dos 16 separados/divorciados, 5 (cinco) atuam como voluntários. Cabe enfatizar que o número dos participantes casados é maior em ambas as categorias, dos que realizam e dos que não estão realizando atividade voluntária, coincidindo com o estudo exposto anteriormente.

No que se refere a filhos, segundo Wilson e Musick (1999), um dos fatores que impulsionam a participação dos voluntários é a presença de crianças no domicílio. E na análise comparativa entre a 
prática do voluntariado e o quantitativo de filhos, apurou-se na amostra que a maioria têm filhos, tanto entre os voluntários como os não voluntários. Deduz-se, assim, que o quantitativo de filhos não aparenta ser um fator impeditivo na tomada de decisão para atuar no voluntariado.

Para Wilson e Musick (1999, p.164), "a educação é um poderoso preditor de voluntariado". Dessa forma, procurou-se averiguar a relação entre a prática do voluntariado e o grau de escolaridade dos participantes e constatou-se que a maior parte dos TAEs voluntários $(72,5 \%)$ têm pós-graduação completa (especialização, mestrado ou doutorado). O nível de instrução elevado entre os voluntários foi também destaque na pesquisa nacional e enfatizou-se que a razão pode ser por conta dos indivíduos com nível superior terem mais acesso à informação, bem como maior conscientização em relação aos demais (IBGE, 2018).

Outra questão a ser analisada é sobre a religiosidade, pois é sabido que a religião influenciou no início do voluntariado no Brasil e continua sendo o principal motivador deste tipo de atividade no país (CAVALCANTE, 2016). Na amostra, averiguou-se a relação da prática do voluntariado com a frequência com que praticam e vivenciam atividades religiosas e a importância da religião na vida dos participantes. O resultado encontrado demonstrou que os TAEs voluntários possuem média maior em ambos os questionamentos em comparação com os não voluntários, ou seja, a frequência com que participam de atividades religiosas teve média 3,63, em escala de cinco pontos, variando de "muito baixa" a "muito alta" e a importância da religião em suas vidas obteve média 4,15, também em escala de cinco pontos. O teste de Mann-Whitney indicou diferenças significativas na prática do voluntariado em relação à participação em atividade religiosa e à importância da religião.

\section{Posicionamento sobre o Voluntariado}

Apurou-se dentre a amostra de TAEs da Univasf que, $65,8 \%$ dos participantes não têm conhecimento sobre o Decreto $\mathrm{n}^{\circ}$ 9.149/2017, que cria o Programa Nacional de Voluntariado (PNV) e institui o Prêmio Nacional de Voluntariado. Em virtude dos problemas apresentados nos últimos tempos e por conta dos índices elevados de desemprego, os responsáveis pelas políticas públicas passaram a prestar atenção na importância do voluntariado dentro do contexto social (SARDINHA, 2011). Ainda sobre as política, questionou-se se a implantação do PNV, juntamente com o incentivo oficial da Administração Pública para a participação dos servidores públicos no voluntariado, é uma polític importante e a média das respostas foi de 3,92, para tanto, foi usada a escala de cinco pontos, variando de "discordo totalmente" a "concordo totalmente". 
Para Bussell e Forbes (2002), os governos passaram a criar iniciativas de desenvolvimento do voluntariado e a incluir nas políticas públicas, após o reconhecimento do valor do tempo de voluntariado, assim como, dos benefícios que podem advir para os indivíduos. Dessa maneira, em virtude da pertinência do voluntariado, este foi incluído entre as políticas de desenvolvimento nacional e resultou na regulamentação da atividade por meio da promulgação do Decreto nº 9.149/2017 (VITALIS, 2015).

Assim, nota-se que, embora o decreto não seja do conhecimento de boa parte da amostra, os servidores públicos são tendentes a concordar que o incentivo ao voluntariado é uma política pública relevante, significando que, para pesquisados, foi acertado incluir o desenvolvimento do voluntariado nacional na pauta da agenda política do governo federal. Isso denota que os TAEs, mesmo a maioria não atuando como voluntário, estão propensos a perceber o voluntariado de forma positiva, uma vez que, ao serem indagados se consideravam o voluntariado uma prática essencial para promoção do bemestar social, a média das respostas foi 4,07, em escala de cinco pontos, variando entre "totalmente desnecessária" a "totalmente necessária".

Sendo o voluntariado oportunidade de atuação direta dos servidores públicos na comunidade local, os mesmos são tendentes a concordar que a participação em ações voluntárias valoriza a categoria perante a sociedade, já que, ao serem questionados, a média dos participantes foi de 3,95, com mesma escala das demais variáveis apresentadas, variando de "discordo totalmente" a "concordo totalmente". Além disso, os TAEs concordam que a prática do voluntariado também agrega valor ao desenvolvimento pessoal do servidor, posto que a média dos respondentes foi de 4,32, na escala de cinco pontos, variando de "discordo totalmente" a "concordo totalmente".

Estudos comprovam que o voluntariado pode ser visto como fonte de enriquecimento e expansão das referências e valores individuais, pois, embora os voluntários não sejam remunerados, estes são favorecidos com a valorização pessoal através do acúmulo de experiências (SARDINHA, 2011). E conforme Santos Ribeiro e Mancebo (2013, p. 206) esta "pode ser significativa oportunidade de desenvolvimento das potencialidades, atuando como fonte de autorrealização, de autoestima, de experiências psicossociais e de sentido de vida". Observa-se que os TAEs pesquisados concordam que a prática do voluntariado agrega valor ao desenvolvimento pessoal do servidor público, isto é, além de perceberem o voluntariado como uma prática essencial para o bem-estar da coletividade, também entendem que os benefícios podem ser pessoais, de autodesenvolvimento.

Quanto à possibilidade do voluntariado agregar valor ao desenvolvimento profissional do servidor público, a média dos TAEs foi de 3,93, na mesma escala de cinco pontos. Confirmando esta percepção, Bussell e Forbes (2002) declaram que o trabalho voluntário permite o desenvolvimento de 
habilidades que podem ser úteis para uma futura carreira, ou até mesmo, para obtenção de emprego ou obtenção de créditos acadêmicos.

Ao serem questionados sobre se a atuação no serviço público incentiva à prática de atividades voluntárias, a média dos respondentes foi de 2,92, na mesma escala de cinco pontos, variando de "discordo totalmente" a "concordo totalmente". Sabe-se que a promoção de atividades voluntárias resulta em benefícios para a própria organização, através da melhoria na sua imagem, na moral e produtividade dos funcionários, assim como para os funcionários, ao permitir que os mesmos possam envolver-se e aprender com outras organizações, facilitando a vida profissional (BUSSELL; FORBES, 2002). Nesse quesito, a Univasf encontra-se aquém dos resultados divulgados em pesquisas sobre voluntariado, posto que a média dos respondentes foi baixa, constatando-se, assim, que os TAEs discordam que o seu ambiente de trabalho o estimulem à participação em atividades voluntárias.

Com base no posicionamento anterior, a população estudada concorda que a Univasf deve adequar-se à proposta do decreto supracitado, desenvolvendo ações para incentivar e envolver os servidores públicos em projetos de extensão em prol da comunidade, visto que, ao serem inquiridos, a média dos participantes foi de 4,07, também em escala de cinco pontos. Sendo a Univasf universidade pública, esta deve cumprir com a responsabilidade social e, sendo pública, a instituição em evidência ainda fica responsável por contribuir para o desenvolvimento do voluntariado, conforme o Decreto 9.149/2017, devendo envolver o seu pessoal neste tipo de atividade.

Assim, baseado no resultado alcançado na pesquisa, nota-se que a instituição tem o apoio dos TAEs no atendimento dos imperativos legais e sociais e a IFES, adequando-se ao decreto, obterá resultados favoráveis para o desenvolvimento do voluntariado.

\section{Desafios e Incentivos à Prática do Voluntariado}

Nota-se que, a percepção sobre os motivos impeditivos para a prática do voluntariado não difere entre os participantes que foram voluntários há menos de 5 anos e os que foram voluntários há mais de 5 anos ou nunca foram voluntários. E com relação às causas escolhidas, a falta de tempo, a incompatibilidade com o horário de trabalho e a dificuldade de conciliar o trabalho voluntário com a vida profissional e/ou pessoal foram bastante destacadas pelos TAEs que não estão atuando como voluntários, demonstrando que a disponibilidade de tempo ainda é fator central para o voluntariado, principalmente, por este ser considerado um recurso escasso (PEREIRA, 2015). 
Em se tratando dos TAEs da Univasf, o resultado auferido pode ser justificado em virtude da jornada de trabalho de 8 horas diárias, conforme a Lei 8.112/1990 e o trabalho em tempo integral significa que a maior parte do dia será utilizada, exclusivamente, para atender as atribuições do cargo público. Assim, é compreensível que tenham alegado a falta de tempo para suspender ou nunca ter participado de atividades voluntárias, visto que podem estar em conflito, e não estão conseguindo conciliar a vida profissional e pessoal com o voluntariado, principalmente, levando em consideração que a maioria dos participantes são casados e têm filhos.

Outro motivo muito escolhido foi a falta de incentivo e de motivação. Considerando que os indivíduos possuem recursos finitos para se dedicar às organizações (BUSSELL; FORBES, 2002), como foi percebida a falta de tempo entre os TAEs, é imprescindível que haja a gestão de voluntários tanto para o recrutamento como também para a retenção dos mesmos. E a questão valorosa é ter a compreensão dos motivos do grupo-alvo de voluntários (BUSSELL; FORBES, 2002). Especialmente, devido às mudanças ambientais, em que há aumento de organizações e diminuição no quantitativo de voluntários, as organizações devem focar na motivação e procurar oferecer algo especial para seus membros, atendendo a demandas individuais (BUSSELL; FORBES, 2002; CAVALCANTE, 2016).

No contexto dos TAEs que foram voluntários há mais de 5 anos ou nunca foram voluntários, o resultado da falta de incentivo e motivação relaciona-se com os resultados do presente estudo quanto ao posicionamento sobre o voluntariado, onde os mesmos não consideram que a sua atuação no setor incentiva a práticas voluntárias. No entanto, são tendentes a considerar a implantação do PNV uma política pública importante, assim como são propensos a considerar que a Univasf deve adequar-se aos normativos legais de incentivo ao voluntariado. Inclusive, ao serem questionados sobre o seu nível de motivação para atuarem como voluntários no futuro, a média dos participantes que foram voluntários há mais de 5 anos foi de 3,49, enquanto que os que nunca foram voluntários tiveram média 3,23, em uma escala de cinco pontos que variava de "muito desmotivado" a "muito motivado", ambos os resultados ficaram próximos de motivado. Cabe enfatizar que o teste de Mann-Whitney demonstrou que não há diferença significativa entre esses dois grupos analisados.

Quanto aos TAEs que foram voluntários há menos de 5 anos, estes ao serem inquiridos sobre o seu nível de motivação para voltar a atuar como voluntários futuramente, a média dos participantes foi 3,82 , na mesma escala de cinco pontos que variava de "muito desmotivado" a "muito motivado". Notase que o resultado ficou próximo de motivado do que os anteriores, demonstrando que lapso temporal influência no comportamento de respondentes que foram voluntários há menos de 5 anos. Compete à Univasf, no cumprimento do decreto presidencial, aproveitar a concordância dos servidores públicos com a implantação do PNV e procurar ajustar as ações de incentivo às motivações dos TAEs. 
No quesito dos incentivos, levando em consideração que é objetivo do PNV estabelecer os meios para que se estimulem o voluntariado, o Governo Federal designou, no Decreto 9.149/2017, algumas possibilidades de utilização das horas de trabalho voluntário no âmbito da Administração Pública para contribuir com uma maior adesão dos servidores públicos. Estabeleceu-se as seguintes possibilidades nos artigos 13 e 17 do supracitado decreto, a saber: (a) utilização das horas de trabalho voluntário como critério de desempate em concursos públicos, (b) utilização em processos internos de promoção nas carreiras, (c) utilização em programas educacionais fomentados pelo Poder Público Federal e nos programas educacionais de ensino, e (d) utilização da licença para capacitação integral ou parcialmente para a realização de atividade voluntária em entidade que preste serviços desta natureza tanto no Brasil quanto no exterior (BRASIL, 2017).

A maioria dos participantes optou pela redução do expediente de trabalho nos dias de ações voluntárias como principal incentivo. Constata-se que esta colocação dos TAEs está em concordância com o posicionamento dos mesmos quando apresentaram a falta de tempo e a incompatibilidade com o horário de trabalho como entraves para prática do voluntariado. Outro incentivo bastante escolhido, por 89 respondentes, foi a possibilidade de utilizar as horas, devidamente comprovadas, de atividades voluntárias em processos de promoção na carreira. A escolha deste complementa o posicionamento dos TAEs de que o voluntariado possibilita ao servidor público o desenvolvimento profissional.

\section{Relações entre o Voluntariado, a Bateria de Personalidade Pró-Social e o Inventário de Funções do Voluntariado}

$\mathrm{Na}$ análise dos traços de personalidade pró-social, obteve-se, através da BPP, a média geral dos participantes nos sete fatores, em que as maiores pontuações indicam uma tendência maior para uma personalidade pró-social, a saber:

A tomada de perspectiva, fator da primeira dimensão, teve média geral de 15,91 e procura avaliar a tendência em assumir a perspectiva de outra pessoa, por exemplo, no item 'Quando estou chateado com alguém, geralmente procuro me colocar em seu lugar' (RABELO; PILATI, 2013). E através deste fator é possível identificar os indivíduos que procuram entender a situação de acordo com o ponto de vista do outro (FERRARI, 2010).

A responsabilidade social, fator também pertencente a primeira dimensão da BPP, apresentou média geral de 12,20. Este fator está relacionado à tendência em assumir a responsabilidade pelas consequências das ações, como, por exemplo, o item 'Eu me sentiria menos incomodado ao deixar lixo 
em um parque sujo do que em um parque limpo' (RABELO; PILATI, 2013). E este é um fator considerado essencial para engajamento em trabalhos voluntários, conforme Finkelstein (2009).

O fator raciocínio moral mútuo, ainda da primeira dimensão da BPP, obteve média geral de 11,81 e representa a junção de itens que têm a tendência de considerar o interesse de todos os envolvidos na tomada de decisões morais, como, por exemplo, no item 'Eu escolho alternativas com a intenção de satisfazer as necessidades de todo mundo' (RABELO; PILATI, 2013). A preocupação empática, fator da primeira dimensão, apresentou média geral de 10,83. Para Rabelo e Pilati (2013), associa-se à tendência de sentimentos direcionados para o próximo, como a simpatia e a preocupação, o item que exemplifica este fator é 'A miséria dos outros geralmente não me incomoda muito.

O raciocínio relacionado ao outro, por sua vez, último fator pertence a primeira dimensão da BPP, teve como média geral 10,75. Este fator representa a tendência em considerar o interesse de todos ao tomar decisões morais, por exemplo, no item 'Minhas decisões são geralmente baseadas na minha preocupação com outras pessoas (RABELO; PILATI, 2013). O altruísmo autorrelatado, fator pertencente a segunda dimensão da BPP, apresentou média geral de 17,68. Segundo Rabelo e Pilati (2013), este fator está associado a uma tendência em ajudar pessoas necessitadas e apresentaram, como exemplo, o item 'Já ajudei a carregar os pertences de um estranho (como livros, pacotes, etc.)'.

E o desconforto pessoal, último fator analisado e pertencente a segunda dimensão, teve média geral de 7,78 e está associado à "propensão a sentimentos de ansiedade e mal-estar voltados para si diante de uma situação interpessoal tensa" (RABELO; PILATI, 2013, p. 458), como, por exemplo, no item 'Quando vejo alguém que precisa de ajuda em uma situação de emergência, eu fico perdido'.

Até o momento, foram discutidos fatores considerados duradouros que incluem personalidade e fatores sociais associados ao voluntariado, no entanto, essas condições, por si só, não determinam se um indivíduo será voluntário (MATSUBA; HART; ATKINS, 2007). Faz-se necessário conhecer a motivação, visto que esta é um importante preditor para a participação em atividades voluntárias e varia entre indivíduos. No presente estudo, utilizou-se o Inventário de Funções do Voluntariado (IFV) para identificar as motivações individuais de natureza genérica para o voluntariado entre os TAEs da Univasf. $\mathrm{Na}$ análise do IFV, obteve-se a média de participantes em quatro funções psicológicas básicas que seriam atendidas, sendo que a função com maior pontuação indica a motivação central, a saber:

A função Social/Engrandecimento teve média geral de 37,12 e é a junção de duas funções. A primeira corresponde aos relacionamentos com os outros, ou seja, está pautada nas oportunidades que o voluntariado proporciona para estar com amigos e de participar de atividades vista favoravelmente por pessoas importantes. A função Valores/Entendimento, junção também de duas funções, apresentou média de 50,58. Para Clary et al. (1998), a função Valores indica a oportunidades que o voluntariado

675 Id on Line Rev. Mult. Psic. V.12, N. 42, p. 659-680, 2018 - ISSN 1981-1179 Edição eletrônica em http://idonline.emnuvens.com.br/id 
fornece para os indivíduos expressarem valores relacionados a preocupações altruístas e humanitárias para os outros. A função Carreira, outra função que pode ser oferecida pelo voluntariado, diz respeito aos benefícios ligados à carreira que podem ser obtidos com a participação no trabalho voluntário, ou seja, experiência profissional (MARQUES, 2016). E a média geral obtida pelos participantes nesta função foi de 14,81 .

E a última função é a da Proteção que apresentou média geral de 16,57. Esta função serve para reduzir a culpa do indivíduo por ser mais afortunado do que outros e para resolver os próprios problemas pessoais (CLARY et al., 1998). Analisando o resultado da média geral dos participantes no IFV, observou-se que a motivação predominante foi da função Valores/Entendimento. Nesse sentido, observa-se que, novamente, o altruísmo está em evidência entre os TAEs pesquisados, juntamente com a percepção de oportunidade de aprendizagem.

\section{Conclusão}

Constata-se, em linhas gerais, que os dados discutidos, por si mesmos, evidenciam a efetiva necessidade de se instituir políticas de voluntariado no serviço público, principalmente no contexto da Univasf. A universidade, enquanto órgão público federal, precisa incluir a temática do incentivo ao voluntariado na sua pauta de discussão, procurando desenvolver estratégias para engajamento dos seus servidores públicos, dentre os quais estão os TAEs.

A pesquisa revelou questões cruciais que a instituição precisa levar em consideração, para ter êxito na implementação da cultura do voluntariado na instituição. A primeira questão, a ser considerada pela Univasf, é em relação ao reconhecimento dos TAEs de que a atuação no serviço público não incentiva para a prática de atividades voluntárias, pois, de acordo com o resultado auferido, eles discordam de que a instituição em que atuam incentive ao exercício da ação voluntária.

O outro ponto a ser considerado pela universidade, talvez em consequência da primeira questão, é o quantitativo de TAEs que estão atuando em atividades voluntárias, dado que, de acordo com a pesquisa, apenas 24,8\% dos participantes são voluntários. Embora, em relação à proporção do voluntariado nacional (IBGE, 2018), a Univasf tenha um quantitativo significativo de voluntários, mesmo assim precisará focar em estratégias de incentivo ao voluntariado.

Questão relevante é a falta de comunicação, sobretudo a interna, uma vez que verificou-se que a maioria dos TAEs não tem conhecimento sobre o decreto presidencial que cria o Programa Nacional de Voluntariado (PNV). A comunicação é uma das áreas vitais para o desenvolvimento de programa de 
voluntariado, devendo ser priorizada desde o início da elaboração, para não comprometer todo o processo. A Univasf deve priorizar a comunicação com o público interno, visando a efetividade da implementação das ações de voluntariado, especialmente, para dar visibilidade à política de incentivo e recrutar mais voluntários.

Como é sabido, o recrutamento e retenção dos voluntários são um dos principais desafios para as organizações, logo, é importante observar empecilhos para a realização da prática do voluntariado, e, conforme a pesquisa, a falta de tempo, incompatibilidade com horário de trabalho, dificuldade de conciliar com a vida pessoal e profissional, falta de incentivo e motivação foram os entraves mais apontados pelos participantes para não ser ou deixar de ser voluntário.

A instituição deve ter em vista que a maioria dos participantes, além da jornada de trabalho de 40 horas semanais, é casada e tem filhos, o que gera conflito na divisão do tempo, devendo, portanto, criar estímulos que possam reverter a situação, como, por exemplo, os incentivos mais propostos pelos TAEs, quais sejam: a redução do expediente nos dias de ações voluntárias e possibilidade de utilização das horas trabalhadas em atividades voluntárias em processos internos de promoção nas carreiras da Administração Pública Federal.

Nota-se que são interesses de âmbito tanto interno como externo, da mesma forma que na análise da personalidade pró-social e na motivação, por meio da BPP e do IFV, ficou demonstrado que os TAEs, voluntários e não voluntários, possuem o altruísmo e os valores como sendo preponderantes na sua vida, motivações que são intrínsecas ao voluntariado. Mas os técnicos administrativos, também, se manifestaram no sentido de que o voluntariado pode agregar valor ao desenvolvimento profissional dos servidores públicos. Assim, o gestor precisa levar em consideração esses dois vieses da motivação, interna e externa, na elaboração de política de incentivo ao voluntariado, visto que é perfeitamente possível a existência simultânea das duas motivações.

Por outro lado, os resultados foram favoráveis para a instituição no sentido em que os TAEs consideram o PNV uma política pública importante, além de concordarem que o voluntariado é uma prática essencial para a promoção do bem-estar. Estas informações indicam que os TAEs percebem a importância do voluntariado e entendem que a prática pode valorizar os servidores públicos perante a sociedade, agregando, também, valor ao desenvolvimento profissional dos mesmos. 


\section{Referências}

AGUIAR, Kássia; SILVA, Alfredo; DIAS, Letícia. As relações simbólicas e a motivação no trabalho voluntário. RAM. Revista de Administração Mackenzie, v. 16, n. 3, 2015.

AGOSTINHO, D. A. R. Voluntariado: uma abordagem às motivações dos voluntários do Banco Alimentar. 2011. Tese de Doutorado. Universidade da Beira Interior (UBI), Covilhã.

BRASIL. Decreto $n^{\circ}$ 9.149, de 28 de agosto de 2017. Cria o Programa Nacional de Voluntariado, institui o Prêmio Nacional do Voluntariado. Disponível em: <http://www.planalto.gov.br/ccivil_03/_ato2015-2018/2017/decreto/D9149.htm> Acesso em: 04 set. 2017.

BUSSELL, Helen; FORBES, Deborah. Understanding the volunteer market: The what, where, who and why of volunteering. International journal of nonprofit and voluntary sector marketing, v. 7, n. 3, p. 244-257, 2002.

CAVALCANTE, Carlos Eduardo. Motivação de voluntários. Appris Editora e Livraria EireliME, 2016.

CAVERO SIBILLE, Eduardo Héctor. El voluntariado universitario en el Perú: el caso de Techo-Perú. 2015. Tesis para optar el grado de Magíster en Sociología. Pontificia Universidad Católica Del Perú (PUCP).

CLARY, E. Gil et al. Compreender e avaliar as motivações dos voluntários: uma abordagem funcional. Jornal de personalidade e psicologia social , v. 74, n. 6, p. 1516, 1998.

COUTINHO, Maria Chalfin; DIOGO, Maria Fernanda; JOAQUIM, Emanuelle de Paula. Sentidos do trabalho e saber tácito: estudo de caso em universidade pública. Psic: revista da Vetor Editora, v. 9, n. 1, p. 99-108, 2008.

FARIA, Renata Mercês Oliveira de; LEITE, Isabel Cristina Gonçalves; SILVA, Girlene Alves da. O sentido da relação trabalho e saúde para os assistentes em administração de uma universidade pública federal no Estado de Minas Gerais. Physis: Revista de Saúde Coletiva, v. 27, p. 541-559, 2017.

FERRARI, Rachele. Voluntariado: uma dimensão ética. $1^{\text {a }}$ ed. São Paulo: Escuta, 2010.

FINKELSTIEN, Marcia A. Intrinsic vs. extrinsic motivational orientations and the volunteer process. Personality and Individual Differences, v. 46, n. 5-6, p. 653-658, 2009.

IBGE. Agência IBGE Notícias sobre o voluntariado no Brasil. 2018. Disponível em: $<$ https://agenciadenoticias.ibge.gov.br/agencia-noticias/2012-agencia-de-

noticias/noticias/20913-voluntariado-aumentou-em-840-mil-pessoas-em-2017.html> Acesso em: 10 jul. 2018. 
MARCOS, Vanessa; AMADOR, Cláudia. A gestão do voluntariado. Empreendedorismo social em Portugal, 2014.

MARQUES, Maria João Ribeiro. As motivações para o voluntariado: estudo exploratório numa amostra de estudantes do ensino superior politécnico. 2016. Tese de Doutorado. Instituto Politécnico de Coimbra.

MATSUBA, M. Kyle; HART, Daniel; ATKINS, Robert. Psychological and social-structural influences on commitment to volunteering. Journal of research in personality, v. 41, n. 4, p. 889-907, 2007.

NEVES, Nancy de Oliveira. O trabalho social voluntário: uma possibilidade para a formação profissional na universidade. 2006. Monografia de Especialização. Universidade do Extremo Sul Catarinense (UNESC).

NOOR, Khairul Baharein Mohd. Case study: A strategic research methodology. American journal of applied sciences, v. 5, n. 11, p. 1602-1604, 2008.

PENNER, Louis A. Dispositional and organizational influences on sustained volunteerism: An interactionist perspective. Journal of social issues, v. 58, n. 3, p. 447-467, 2002.

PEREIRA, Gabriela Moreira. Análise económica da dimensão relacional do voluntariado. 2015. Tese de Doutorado. Instituto Universitário de Lisboa (IUL).

PILATI, Ronaldo; HEES, Maria Alexandra Gaiofatto. Evidências de validade de uma versão brasileira do Inventário de Funções do Voluntariado-IFV. Psico-USF, v. 16, n. 3, p. 275-284, 2011.

RABELO, André LA; PILATI, Ronaldo. Adaptação e evidências de validade da Bateria de Personalidade Prosocial no Brasil. Psico-USF, v. 18, n. 3, p. 455-468, 2013.

RAMOS, S. P. B. Voluntariado universitário: a solidariedade nos corredores de uma faculdade. 2012. Tese de Doutorado. Universidade da Beira Interior (UBI).

RIBEIRO, Carla Vaz dos Santos; MANCEBO, Deise. The public servant in the labor world Of The 21St century. Psicologia: Ciência e Profissão, v. 33, n. 1, p. 192-207, 2013.

RODRIGUES, Kleberson Massaro et al. Voluntariado: um estudo bibliométrico e sociométrico da produção científica da temática da Revista Voluntas (1997-2012). Perspectivas Contemporâneas, v. 9, n. 2, p. 150-166, 2014.

SAPIRO, A.; MATTIELLO, R. Voluntariado: benefício a quem presta e a quem recebe. Scientia Medica, v. 26, n. 4, p. 1-5, 2016. 
SARDINHA, Boguslawa Maria Barszczak. Voluntariado na economia: um recurso em valorização. Hospitalidade, n. 293, p. 16-21, 2011.

SELLI, L.; GARRAFA, V. Solidariedade crítica e voluntariado orgânico: outra possibilidade de intervenção societária. História, Ciências, Saúde-Manguinhos, v. 13, n. 2, p. 239-251, 2006.

SODRÉ, M. C. A. (Consult.). Produto 2 - Versão Final: Perspectivas para um sistema nacional de voluntariado. Brasília, 2012. Disponível em: <http://www.cbve.org.br/?p=3478> Acesso em: 05 jan. 2018.

THIEL, Renato. Jovens universitários em projetos de voluntariado socioeducativo: perfil, motivações, impactos. 2012. Dissertação de mestrado. Universidade Católica de Brasília.

VITALIS, Aline. A atuação voluntária na administração pública como instrumento de cidadania ativa, à luz do direito português e brasileiro. Revista CEJ, v. 19, n. 66, p. 80-87, 2015.

WILSON, John.Volunteering. Annual Review of Sociology, 26, p. 215-240, 2000.

WILSON, John; MUSICK, Marc. The effects of volunteering on the volunteer. Law and contemporary problems, v. 62, n. 4, p. 141-168, 1999.

Como citar este artigo (Formato ABNT):

RIBEIRO, Dâmaris Yana; PINHEIRO, Francisco Alves; SAMPAIO, Leonardo Rodrigues. O Voluntariado e o Servidor Público: o Caso dos Técnico-Administrativos em Educação da Universidade Federal do Vale do São Francisco (UNIVASF). Id on Line Rev.Mult. Psic., 2018, vol.12, n.42, p. 659-680. ISSN: 1981-1179.

Recebido: 04/10/2018;

Aceito: 17/10/2018 